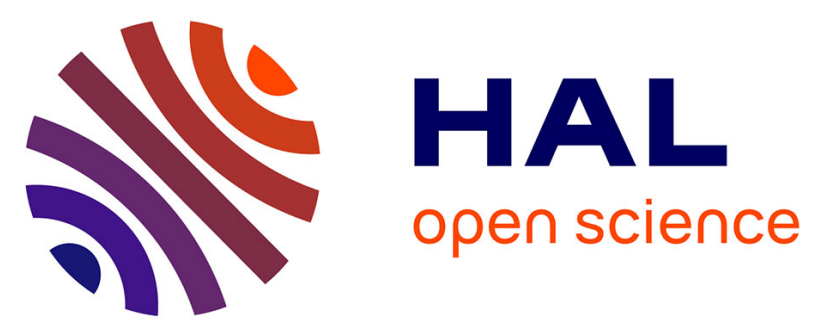

\title{
Rationale, study design and analysis plan of the lung imaging morphology for ventilator settings in acute respiratory distress syndrome study (LIVE study): Study protocol for a randomised controlled trial
}

Matthieu Jabaudon, Thomas Godet, Emmanuel Futier, Jean-Etienne Bazin,

Vincent Sapin, Laurence Roszyk, Bruno Pereira, Jean-Michel Constantin

\section{To cite this version:}

Matthieu Jabaudon, Thomas Godet, Emmanuel Futier, Jean-Etienne Bazin, Vincent Sapin, et al.. Rationale, study design and analysis plan of the lung imaging morphology for ventilator settings in acute respiratory distress syndrome study (LIVE study): Study protocol for a randomised controlled trial. Anaesthesia Critical Care \& Pain Medicine, 2017, 36 (5), pp.301 - 306. 10.1016/j.accpm.2017.02.006 . hal-01919201

\author{
HAL Id: hal-01919201 \\ https://hal.science/hal-01919201
}

Submitted on 12 Nov 2018

HAL is a multi-disciplinary open access archive for the deposit and dissemination of scientific research documents, whether they are published or not. The documents may come from teaching and research institutions in France or abroad, or from public or private research centers.
L'archive ouverte pluridisciplinaire HAL, est destinée au dépôt et à la diffusion de documents scientifiques de niveau recherche, publiés ou non, émanant des établissements d'enseignement et de recherche français ou étrangers, des laboratoires publics ou privés. 


\section{Accepted Manuscript}

Title: Rationale, study design, and analysis plan of the Lung Imaging morphology for Ventilator settings in acute respiratory distress syndrome study (LIVE study): study protocol for a randomised controlled trial

Authors: Matthieu Jabaudon Thomas Godet Emmanuel Futier

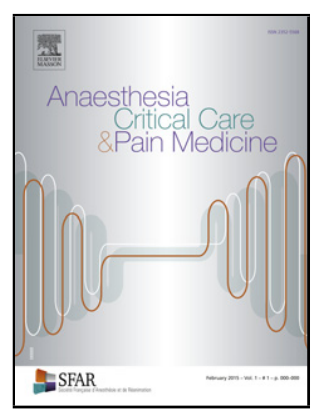
Jean-Etienne Bazin Vincent Sapin Laurence Roszyk Bruno Pereira Jean-Michel Constantin, for AZUREA group

PII: S2352-5568(17)30030-9

DOI: http://dx.doi.org/doi:10.1016/j.accpm.2017.02.006

Reference: ACCPM 242

To appear in:

Received date: 2-2-2017

Revised date: $5-2-2017$

Accepted date: 6-2-2017

Please cite this article as: Matthieu JabaudonThomas GodetEmmanuel FutierJeanEtienne BazinVincent SapinLaurence RoszykBruno PereiraJean-Michel Constantinfor AZUREA group, Rationale, study design, and analysis plan of the Lung Imaging morphology for Ventilator settings in acute respiratory distress syndrome study (LIVE study): study protocol for a randomised controlled trial (2017), http://dx.doi.org/10.1016/j.accpm.2017.02.006

This is a PDF file of an unedited manuscript that has been accepted for publication. As a service to our customers we are providing this early version of the manuscript. The manuscript will undergo copyediting, typesetting, and review of the resulting proof before it is published in its final form. Please note that during the production process errors may be discovered which could affect the content, and all legal disclaimers that apply to the journal pertain. 
Rationale, study design, and analysis plan of the Lung Imaging morphology for Ventilator settings in acute respiratory distress syndrome study (LIVE study): study protocol for a randomised controlled trial.

Matthieu Jabaudon ${ }^{1,2}$, Thomas Godet ${ }^{1,2}$, Emmanuel Futier ${ }^{1,2}$, Jean-Etienne Bazin ${ }^{1}$, Vincent Sapin $^{2,3}$, Laurence Roszyk ${ }^{2,3}$, Bruno Pereira ${ }^{4}$, Jean-Michel Constantin ${ }^{1,2}$ for AZUREA group.

${ }^{1}$ Department of Perioperative Medicine, University Hospital of Clermont-Ferrand, ClermontFerrand, France

${ }^{2}$ Université Clermont Auvergne, CNRS, Inserm, GReD, F-63000 Clermont-Ferrand, France

${ }^{3}$ Department of Medical Biochemistry and Molecular Biology, University Hospital of Clermont-Ferrand, Clermont-Ferrand, France

4 Biostatistics Unit, Department of Clinical Research and Innovation (DRCI), University Hospital of Clermont-Ferrand, Clermont-Ferrand, France

Corresponding author: Pr JM Constantin, Department of Perioperative Medicine, University Hospital of Clermont-Ferrand. jmconstantin@ chu-clermontferrand.fr

\title{
Disclosure of interest
}

The authors declare that they have no conflicts of interest concerning this article.

\begin{abstract}
Different acute respiratory distress syndrome (ARDS) phenotypes may explain controversial results in clinical trials. Lung-morphology is one of the ARDS-phenotypes and physiological studies suggest different responses in terms of positive-end-expiratory-pressure (PEEP) and recruitment-manoeuvres (RM) according to loss of aeration. To evaluate whether
\end{abstract}


tailored ventilator regimens may impact ARDS outcomes, our group has designed a randomised-clinical-trial of ventilator settings according to lung morphology in moderate-tosevere ARDS (LIVE study).

Method: Patients will be enrolled within the first 12 hours of ARDS onset. In both groups, volume-controlled ventilation with low tidal-volumes (Vt) will be used to target a plateau pressure $\leq 30 \mathrm{cmH}_{2} \mathrm{O}$. In the control group, the PEEP level and inspired fraction of oxygen (FiO2) will be set using the ARDSNet table; a Vt of $6 \mathrm{~mL} / \mathrm{kg}$ of predicted body weight (PBW) will be set, and prone position (PP) will be applied. In the intervention arm, the ventilator will be set according to lung morphology (focal/non-focal) that will be assessed according to CT-scan \pm chest $\mathrm{x}$-ray + lung echography. For focal ARDS patients, a Vt of $8 \mathrm{~mL} / \mathrm{kg}$ PBW will be used along with low PEEP and PP. For non-focal ARDS patients, a Vt of $6 \mathrm{~mL} / \mathrm{kg}$ PBW will be used with RM and PEEP to reach a plateau pressure $\leq 30 \mathrm{cmH}_{2} \mathrm{O}$. The primary outcome is all-cause 90-day mortality, and the secondary outcomes are: inhospital mortality, mortality at day $28,60,180$ and 365 ; ventilator-free days at day 30 , quality of life at one year; ventilator-associated pneumonia rate; barotrauma; ICU and hospital length of stay. This RCT is registered on Clinicaltrials.gov under identifier NCT02149589. 
Rationale, study design, and analysis plan for the Lung Imaging morphology for Ventilator settings in acute respiratory distress syndrome study (LIVE study): study protocol for a randomised controlled trial.

\section{Introduction}

Acute respiratory distress syndrome (ARDS) is a common problem in critically ill patients, with a prevalence higher than $10 \%$ of intensive care unit (ICU) admissions [1]. ARDS is associated with high in-hospital mortality (around 40\%) and reduced quality of life among survivors [1,2]. Optimal ventilator management for patients with ARDS remains uncertain. Lower tidal volume (Vt) ventilation appears to be beneficial [3], but the optimal setting of $\mathrm{Vt}$ in a given patient remains uncertain and challenging [4]. Optimal management of positive end-expiratory pressure (PEEP) remains unclear. Higher levels of PEEP have only shown equivocal benefits on outcomes in clinical trials [5,6]. Considering a prone position (PP), data published in the last ten years remain controversial on the benefit of applying PP to all patients with ARDS [7].

One hypothesis that may explain such controversial results is that behind the Berlin definition [8], different patients with distinct forms (or phenotypes) of ARDS may exist. Numerous studies have been published in this field, from the response to mechanical ventilation to the concept of ARDS phenotypes [9-12]. Recent data suggest that lung morphology may be one of the ARDS phenotypes $[13,14]$.

Morphological characterization of CT-scan lung attenuation has contributed to the recognition of subgroups of ARDS patients with distinct therapeutic responses (e.g., to PEEP, recruitment manoeuvres (RM) ...) [15] [16]. Non-focal ARDS, as defined by diffuse lung aeration loss, is usually associated with significant lung recruitability, whereas focal ARDS is characterized 
by predominant aeration loss in lower lobes and dependent lung regions, with low recruitability. Therefore, high PEEP levels and RMs seem more suitable for patients with non-focal ARDS and may rather generate hyperinflation and haemodynamic instability in patients with focal ARDS. Notwithstanding these physiological studies, whether or not such ventilator setting strategies may influence the clinical outcomes of ARDS patients has never been explored. To further explore the impact of tailored ventilation based on lung morphology, we designed a randomised clinical trial of ventilator settings according to lung morphology in moderate-to-severe ARDS. This paper describes the study protocol and planned analyses for this clinical trial, registered on ClinicalTrials.gov under number NCT02149589.

\section{Methods}

\section{Objectives}

Our primary objective is to determine if ventilator settings determined according to lung morphology (focal or non-focal ARDS; the LIVE strategy) decrease the 90-day mortality rate in patients with moderate-to-severe ARDS compared with conventional management (ARDSNet strategy) [17]. The secondary objectives are to evaluate the effects of the LIVE strategy, compared to the ARDSNet strategy, on the following outcomes: in-hospital mortality, mortality at day 28 , day 60 , day 180 and day 365 , ventilator-free days at day 30 , quality of life at one year, ventilator-associated pneumonia rate, barotrauma (pneumothorax, pneumomediastinum), ICU and hospital lengths of stay.

\section{Ethics and communication}

Ethical details are in the main manuscript. 
The study was approved by an independent ethics committee (Comité de Protection des Personnes Sud-Est VI, Clermont Ferrand, France; number: AU1099) and registered by the French competent authority (Agence nationale de sécurité du médicament (ANSM); number: 2013-A01756-39).

\section{Study design}

Live is an investigator-initiated, patient-blinded, randomised, stratified, controlled, multicentre trial with allocation and intention-to-treat analysis. Patients with ARDS will be treated according to their lung morphology (LIVE strategy), as compared to an ARDSNet strategy.

\section{Study population}

Inclusion criteria

- $\quad$ Age $>18$ years

- Onset of ARDS < 12 hours

- $\mathrm{PaO}_{2} / \mathrm{FiO}_{2} \leq 200 \mathrm{mmHg}$ with $\mathrm{PEEP} \geq 5 \mathrm{cmH}_{2} \mathrm{O}$

Non-inclusion criteria

- Mechanical ventilation for more than 7 consecutive days in the last 30 days.

- Previous history of ARDS in the last month

- Intracranial hypertension

- Morbid obesity with body mass index $>40 \mathrm{~kg} / \mathrm{m}^{2}$

- Chronic respiratory diseases requiring long-term oxygen therapy

- Allogeneic bone marrow transplantation

- Metastatic cancer 
- Burn patients

- Liver cirrhosis with basal Child and Pugh of C

- Bronchopleural fistula

- Moribund patient

- Pregnancy

- Patient already enrolled in another interventional study

\section{Sample size}

For this study, $2 \times 210$ patients are needed to detect a hazard ratio of 1.45 in the censored primary outcome at a two-sided $\alpha$ level of 0.05 and a statistical power of $90 \%$, assuming a $33 \%$ survival in the control group according to Papazian et al. [18] (i.e., a difference between $33 \%$ and $20 \%$ in between-group mortality rates at 90 days).

\section{Screening}

Patients will be recruited from 21 clinical sites in France with experience in the identification and management of ARDS. A full list of the participating institutions is displayed in Table 1. The resulting study population is expected to be representative of the French adult acute care hospital population. Study coordinators at each site will visit the ICUs at least daily to identify potential candidates for enrolment. Screening logs will be maintained at each site and sent to the study coordinator every month. Once a patient is deemed eligible for the study, the designated substitute decision maker will be approached by a study investigator to give informed consent. Due to the short window of inclusion, less than 12 hours after ARDS onset, an emergency inclusion procedure will be possible. In this case, inclusion will be validated by both a local investigator and an independent physician from outside the ICU. 
All patients with inclusion criteria and without non-inclusion criteria will be eligible for inclusion in the study. After sedation and paralysation by neuromuscular blockers, a blood gas analysis will be required at baseline. Lung morphology will be assessed by CT-scan. If the physician considers the patient non-transportable to the department of radiology, a chest x-ray \pm lung echography could be used. The local investigator in charge of patient inclusion will define lung morphology, focal or non-focal [19]. A second analysis including 1 radiologist and two intensivists, blinded from patient history and randomisation allocation arm, will be performed after the end of trial inclusions for post-hoc analysis.

\section{Randomisation}

Patients will be randomised in a 1:1 ratio through centralised computer randomization (www.tenalea.com) to the LIVE strategy (interventional group) or the ARDSNet strategy (control group) stratified by investigator centre, lung morphology, and duration of mechanical ventilation before ARDS onset ( $>48$ hours or $<48$ hours). The random allocation will be done with a dynamic balanced randomization, a method balancing treatment allocations both within strata and across the trial as a whole. The method keeps a running tally on total treatment allocation numbers at all stratification levels. When a patient accrues a hierarchical decision rule is applied, and the allocation is deterministic if certain pre-defined limits are exceeded, and random otherwise [20].

\section{Interventions}

In both randomisation groups, patients will be paralysed (with cis-atracurium) and sedated. In both arms, tidal volume (VT) will be set according to predicted body weight (PBW). Predicted body weight should be calculated for all patients according to the formula:

- Men: PBW $(\mathrm{kg})=50+2.3(($ height $[\mathrm{cm}] \times 0.394)-60)$ 
- Women: PBW $(\mathrm{kg})=45.5+2.3(($ height $[\mathrm{cm}] \times 0.394)-60)$

The oxygenation target will be the same for both groups, with $\mathrm{SpO} 2>88 \%$ or $\mathrm{PaO} 2$ $>55 \mathrm{mmHg}$.

Investigators will be encouraged to follow ICU guidelines for ventilator associated pneumonia, sedation, nutrition, and the surviving sepsis campaign, but no one guideline will be mandatory in terms of the global management of ICU patients.

\section{Control group}

In the control arm, the ventilator strategy will be the ARDSNet strategy, with VT=6 ml/kg of PBW, PEEP according to $\mathrm{FiO}_{2}$ (Table 2) and an early prone position (PP) as soon as possible after randomisation. A maximal inspiratory plateau pressure (Pplat) of $30 \mathrm{cmH}_{2} \mathrm{O}$ will be targeted. In case of higher Pplat, PEEP will be decreased to keep Pplat $<30 \mathrm{cmH}_{2} \mathrm{O}$.

\section{Interventional group}

For the LIVE strategy groups, ventilators will be set according to lung morphology.

In patients with focal ARDS, VT will be $8 \mathrm{ml} / \mathrm{kg}$ of PBW, PEEP will be set minimally between 5 to $10 \mathrm{cmH}_{2} \mathrm{O}$ according to oxygenation targets, and $\mathrm{PP}$ will be required in the first two hours after randomisation for a duration of 16 hours.

In patients with non-focal ARDS, VT will be set at $6 \mathrm{ml} / \mathrm{kg}$ of PBW and PEEP will be increased to reach a Pplat of $30 \mathrm{cmH}_{2} \mathrm{O}$ [5]. Immediately afterwards, a RM will be performed. After the RM, PEEP will be increased to reach a Pplat of $30 \mathrm{cmH}_{2} \mathrm{O}$. If oxygenation improves and reaches targeted levels, the PEEP level will remain the same until the patient is switched to pressure support ventilation (PSV). If $\mathrm{SaO}_{2}$ or $\mathrm{PaO}_{2}$ decreases after initial improvement, the VT should be decreased to $5.5 \mathrm{ml} / \mathrm{kg}$ of PBW and PEEP increased to reach a Pplat of 30 
$\mathrm{cmH}_{2} \mathrm{O}$ after a new RM. This process can be performed until VT $=4 \mathrm{ml} / \mathrm{kg}$ of PBW. RMs should be repeated, if necessary, to maintain a steady $\mathrm{SpO}_{2}$.

In both arms, as soon as $\mathrm{PaO}_{2} / \mathrm{FiO}_{2}>200 \mathrm{mmHg}$ for 4 hours with $\mathrm{FiO}_{2}<0.6$, or 48 hours after inclusion, neuromuscular blockers will be discontinued, the level of sedation targeted to a Richmond Agitation-Sedation Scale (RASS) of 0/-1, and the ventilator mode switched to PSV. In case of failure of PSV to maintain adequate gas exchange $\left(\mathrm{PaO}_{2} / \mathrm{FiO}_{2}>200 \mathrm{mmHg}\right.$ for 4 hours with $\mathrm{FiO}_{2}<0.6$ ), sedation should be increased, neuromuscular blockers should be restarted if they have been used for less than 48 hours, and the ventilator set back to volumecontrolled ventilation, according to the allocation arm. If neuromuscular blockers have already been used for 48 hours, they should be used again only as rescue therapy. When $\mathrm{PaO}_{2} / \mathrm{FiO}_{2}$ is above $200 \mathrm{mmHg}$ for 4 hours with $\mathrm{FiO}_{2}<0.6$, the same procedure should be used again. All study interventions are summarised in Figure 1.

\section{Blood Samples}

Blood samples will be obtained at baseline (after randomisation and before initiation of study interventions), then on days 1, 2, 3, 4 and 7 after inclusion. All blood samples will be stored after centrifugation at $-80^{\circ} \mathrm{C}$ until further analysis. Biomarkers of interest are listed in Table 3 .

\section{Statistical methods}

Statistical analysis will be conducted on an intention-to-treat (ITT) basis. The time-to-event curves will be estimated with the use of the Kaplan-Meier method, particularly for the primary outcome. An unadjusted log-rank test will be considered for the primary analysis. Then, adjusted analysis will be performed using marginal Cox proportional hazard regression, (1) to take into account adjustment on possible confounding covariates selected according to clinical relevance (age, SAPS II score, Baseline $\mathrm{PaO}_{2} / \mathrm{FiO}_{2}$, SOFA score at inclusion, ), and (2) to consider within- and between-centre variability (as a random effect). Results will be 
expressed as hazard-ratios with 95\% confidence intervals. The chi-square test (or Fisher's exact test as appropriate) will be used for secondary categorical outcomes. Continuous variables will be compared with the use of the unpaired $t$ test or the Mann-Whitney $U$ test when appropriate. The Shapiro-Wilk test will be used to assess normality, and the FisherSnedecor test to assess homoscedasticity. Adjusted analyses will be performed using the same adjustment variables as described previously in the regression model (linear for quantitative dependent outcomes and logistic for dichotomous variables). If the frequency of missing data is $>5 \%$, an additional analysis will be performed using the multiple imputation method.

Subgroups analyses are planned, according to clinical relevance. A particular attention will be paid to analysis among Berlin classification and focal and non-focal ARDS. Before the subgroup analysis, the interaction sub-group $x$ randomized group will be studied in the regression models previously described.

Longitudinal analysis using mixed models will be used to study fixed effect groups, timepoints evaluation and their interaction, taking into account between and within subject variability. Imputation approaches developed by Verbeke and Molenberghs will be privileged. A learning curve analysis will be performed to evaluate if an improvement in terms of primary outcome is observed over time. As proposed by JA Cook et al. (Clinical Trials 2004), this effect will be analysed using Bayesian hierarchical models, useful for adjusting trial results for the existence of a learning curve effect. In the same way, a comparison between centres familiar with RMs and other centres will be performed.

The analysis of concordance between radiologists and clinicians concerning specification of focal and non-focal ARDS will be performed using the kappa concordance coefficient (noted k). Results will be expressed as k, 95\% confidence intervals and accuracy rates and will be compared to values proposed in certain recommendations such as Partik et al. (2002). A 
modified per-protocol analysis will be proposed according to this concordance study, considering focal and non-focal ARDS proposed by the radiologist.

All analyses will be conducted with Stata statistical software, version 13 (StataCorp LP, College Station, TX, USA). A two-sided $P$ value of less than 0.05 will be considered to indicate statistical significance.

\section{Role of the data safety and monitoring board (DSMB)}

Safety oversight will be under the direction of an independent data safety and monitoring board (DSMB). All serious adverse events will be reported to the site Institutional Review Board within $24 \mathrm{~h}$ of the research team learning about the event. The medical coordinating centre will prepare summaries of all reports and provide them to the DSMB at least every 6 months. The DSMB will convene by teleconferencing or in person at $25 \%, 50 \%$ and $75 \%$ of enrolment to review adverse events or earlier if so needed. 


\section{Discussion}

During the last 50 years of intense research on ARDS, few interventions have shown their efficiency in decreasing mortality. Apart from lower tidal volume ventilation (2 studies) [21,22], prone position (one study) [23] and neuromuscular blockers (one study) [24], all other interventions have been associated with negative results $[5,17,25]$. One hypothesis that may explain this situation is that different ARDS phenotypes require different interventions. Lung morphology is one ARDS phenotype, among others, and several studies highlighted distinct responses to ventilator settings in patients with focal versus non-focal ARDS. However, the effects of such a strategy on important patient outcomes remain to be established. Therefore, evidence from well-designed and conducted trials is essential to answer this question.

Here, we present the study protocol and data analysis plans for a new study of mechanical ventilation settings in ARDS. This study is, to our knowledge, the first prospective RCT of personalized ventilator settings in ARDS patients, which can be considered both as a strength and a weakness, due to the exploratory design of such an intervention. If our study finds that a strategy of alveolar recruitment plus PEEP titration for non-focal ARDS, and of prone position plus low PEEP and higher tidal volume ventilation for focal ARDS is beneficial, this will represent a valuable improvement for the management of patients with ARDS. In case of negative results, we should analyse why moving from physiological evidence to clinical evidence may change results and beliefs.

The assessment of lung morphology will be crucial in the LIVE trial. In expert studies, misclassifications or non-agreement between experts occurred in less than 5\% of cases [15]. Most investigators may not be so familiar with lung morphology assessment, and CT-scan 
will not be mandatory. As a result, predicting the degree of misclassification is impossible $a$ priori. When we designed the study, we decided not to require an expert assessment of lung morphology at inclusion, in order to better represent real life conditions. A post-hoc analysis will be done with an expert classification of lung morphology, and according to plasma sRAGE levels. Indeed, plasma sRAGE is well correlated with lung morphology and has been proposed as a surrogate for lung morphology in ARDS [13].

More broadly, a "negative" result remains a crucial result by providing important information to the critical care community and suggests a shift of focus to more fruitful therapeutic interventions. A lack of efficacy in the primary outcome may be offset by new findings in the analysis of secondary outcomes, which could guide future research. In addition, the physiological and biochemical data generated during the exploration of mechanistic outcomes should lead to important insights into the reasons behind the negative result and generation of important new knowledge. Finally, this study will allow, for the first time, the prospective evaluation of ARDS phenotypes, and their related endotypes based on biomarker measurements [12], their relationships with ARDS phenotypes of lung morphology, and perhaps more importantly, their additional values to better understand the response to personalized mechanical ventilation in patients with ARDS. 


\section{Acknowledgements}

The authors thank Sandrine Thibault, Dominique Morand and Lucile Barao for their helpful collaboration in the steering committee.

\section{References:}

[1] Bellani G, Laffey JG, Pham T, Fan E, Brochard L, Esteban A, et al. Epidemiology, Patterns of Care, and Mortality for Patients With Acute Respiratory Distress Syndrome in Intensive Care Units in 50 Countries. Jama 2016;315:788-13. doi:10.1001/jama.2016.0291.

[2] Herridge MS, Tansey CM, Matté A, Tomlinson G, Diaz-Granados N, Cooper A, et al. Functional disability 5 years after acute respiratory distress syndrome. N Engl J Med 2011;364:1293-304. doi:10.1056/NEJMoa1011802.

[3] Needham DM, Yang T, Dinglas VD, Mendez-Tellez PA, Shanholtz C, Sevransky JE, et al. Timing of Low Tidal Volume Ventilation and Intensive Care Unit Mortality in Acute Respiratory Distress Syndrome. A Prospective Cohort Study. Am J Respir Crit Care Med 2015;191:177-85. doi:10.1164/rccm.201409-1598OC.

[4] Protti A, Cressoni M, Santini A, Langer T, Mietto C, Febres D, et al. Lung Stress and Strain During Mechanical Ventilation: Any Safe Threshold? Am J Respir Crit Care Med 2011. doi:10.1164/rccm.201010-1757OC.

[5] Mercat A, Richard J-CM, Vielle B, Jaber S, Osman D, Diehl J-L, et al. Positive endexpiratory pressure setting in adults with acute lung injury and acute respiratory distress syndrome: a randomized controlled trial. Jama 2008;299:646-55. doi:10.1001/jama.299.6.646.

[6] Brower RG, Lanken PN, MacIntyre N, Matthay MA, Morris A, Ancukiewicz M, et al. Higher versus lower positive end-expiratory pressures in patients with the acute respiratory distress syndrome. N Engl J Med 2004;351:327-36.

doi:10.1056/NEJMoa032193.

[7] Bloomfield R, Noble DW, Sudlow A. Prone position for acute respiratory failure in adults. Chichester, UK: John Wiley \& Sons, Ltd; 1996.

doi:10.1002/14651858.CD008095.pub2.

[8] The ARDS Definition Task Force. Acute Respiratory Distress SyndromeThe Berlin DefinitionThe Berlin Definition of ARDS. Jama 2012;307:1-2533.

doi:10.1001/jama.2012.5669.

[9] Gattinoni L, Caironi P, Cressoni M, Chiumello D, Ranieri VM, Quintel M, et al. Lung recruitment in patients with the acute respiratory distress syndrome. N Engl J Med 2006;354:1775-86. doi:10.1056/NEJMoa052052.

[10] Rouby J, Puybasset L, Nieszkowska A, Lu Q. Acute respiratory distress syndrome: lessons from computed tomography of the whole lung. Crit Care Med 2003;31:S285.

[11] Calfee CS, Janz DR, Bernard GR, May AK, Kangelaris KN, Matthay MA, et al. Distinct Molecular Phenotypes of Direct Versus Indirect ARDS in Single and MultiCenter Studies. Chest 2014. doi:10.1378/chest.14-2454.

[12] MD DCSC, PhD PKD, MD PPEP, MD PBTT, MD PLBW, MD PMAM, et al. ArticlesSubphenotypes in acute respiratory distress syndrome: latent class analysis of data from two randomised controlled trials. The Lancet Respiratory 2014:1-10. 
[13] MD SM, Md MJ, PhD SJM, PhD CP-BM, PhD J-YLM, PhD J-JRM, et al. Elevated Plasma Levels of sRAGE Are Associated With Nonfocal CT-Based Lung Imaging in Patients With ARDS. Chest 2016;150:998-1007. doi:10.1016/j.chest.2016.03.016.

[14] Jabaudon M, Blondonnet R, Lutz J, Roszyk L, Bouvier D, Guérin R, et al. Net alveolar fluid clearance is associated with lung morphology phenotypes in acute respiratory distress syndrome. Anaesthesia Critical Care \& Pain Medicine 2016:1-6. doi:10.1016/j.accpm.2015.11.006.

[15] Constantin J-M, Grasso S, Chanques G, Aufort S, Futier E, Sebbane M, et al. Lung morphology predicts response to recruitment maneuver in patients with acute respiratory distress syndrome. Crit Care Med 2010;38:1108-17. doi:10.1097/CCM.0b013e3181d451ec.

[16] Puybasset L, Gusman P, Muller J, Cluzel P, Coriat P, Rouby J. Regional distribution of gas and tissue in acute respiratory distress syndrome. III. Consequences for the effects of positive end-expiratory pressure. Intensive Care Medicine 2000;26:121527.

[17] Brower R, Lanken P, MacIntyre N, Matthay M, Morris A, Ancukiewicz M, et al. Higher versus lower positive end-expiratory pressures in patients with the acute respiratory distress syndrome. N Engl J Med 2004;351:327.

[18] Papazian L, Forel J, Gacouin A, Penot-Ragon C, Perrin G, Loundou A, et al. Neuromuscular blockers in early acute respiratory distress syndrome. New England Journal of Medicine 2010;363:1107-16.

[19] Mrozek S, Jabaudon M, Jaber S, Paugam-Burtz C, Lefrant J-Y, Rouby J-J, et al. Elevated Plasma Levels of sRAGE are Associated with Non-Focal CT-Based Lung Imaging in ARDS patients.: A Prospective Multicenter Study. Chest 2016:1-31. doi:10.1016/j.chest.2016.03.016.

[20] Signorini DF, Leung O, Simes RJ, Beller E, Gebski VJ, Callaghan T. Dynamic balanced randomization for clinical trials. Stat Med 1993;12:2343-50.

[21] Amato MB, Barbas CS, Medeiros DM, Magaldi RB, Schettino GP, Lorenzi-Filho G, et al. Effect of a protective-ventilation strategy on mortality in the acute respiratory distress syndrome. N Engl J Med 1998;338:347-54.

[22] de Campos T. Ventilation with lower tidal volumes as compared with traditional tidal volumes for acute lung injury and the acute respiratory distress syndrome. The Acute Respiratory Distress Syndrome Network. N Engl J Med 2000;342:1301-8.

[23] Guérin C, Reignier J, Richard J-C, Beuret P, Gacouin A, Boulain T, et al. Prone Positioning in Severe Acute Respiratory Distress Syndrome. N Engl J Med 2013:130520110015000. doi:10.1056/NEJMoa1214103.

[24] Papazian L, Forel J-M, Gacouin A, Penot-Ragon C, Perrin G, Loundou A, et al. Neuromuscular blockers in early acute respiratory distress syndrome. N Engl J Med 2010;363:1107-16. doi:10.1056/NEJMoa1005372.

[25] Taccone P, Pesenti A, Latini R, Polli F, Vagginelli F, Mietto C, et al. Prone Positioning in Patients With Moderate and Severe Acute Respiratory Distress Syndrome: A Randomized Controlled Trial. Jama 2009;302:1977. 
- $\quad$ CHU de Clermont-Ferrand - Service de Réanimation Adultes

- Hospice Civils de Lyon - Service d'Anesthésie-Réanimation

- $\quad$ CHU de Montpellier - Hôpital St Eloi - Service de Réanimation Chirurgicale DAR B

- AP- Hôpitaux de Marseille - Service de Réanimation

- CHU de Nîmes - Service de Réanimation Chirurgicale

- $\quad$ CHU de Nantes - Service d'Anesthésie-Réanimation Chirurgicale

- AP-Hôpitaux de Paris - Service d'Anesthésie-Réanimation

- Centre Hospitalier Le Puy en Velay - Service de Réanimation

- CHU de Nice - Service d'Anesthésie-Réanimation

- $\mathrm{CHU}$ de Poitiers - Service d'Anesthésie-Réanimation

- Centre Jean-Perrin Clermont-Ferrand - Service de Réanimation

- $\quad$ CHU de Clermont-Ferrand - Service de Réanimation Médicale Polyvalente

- CHU d'Amiens - Service de Réanimation Chirurgicale

- CHU d'Angers - Service d'Anesthésie-Réanimation chirurgicale

- $\mathrm{CHU}$ de Rennes - Service de Réanimation chirurgicale

- CHU de Rouen - Service de Réanimation Chirurgicale

- CHU de Dijon-Service de Réanimation médicale

- CHU de Tours - Service de Réanimation chirurgicale

- Centre Hospitalier de Cannes - Service de Réanimation

- Centre Hospitalier de St Brieuc - Service de Réanimation

- Centre Hospitalier du Mans - Service de Réanimation médico-chirurgicale

Table 1: Trial centres at study initiation. 
Table 2: ARDSNet table of FiO2 and PEEP values to maintain $\mathrm{SpO}_{2} \geq 88 \%$ or $\mathrm{PaO}_{2} \geq 55 \mathrm{mmHg}$ with a Pplat $\leq 30 \mathrm{cmH}_{2} \mathrm{O}$.

\begin{tabular}{|c|c|}
\hline $\mathrm{FiO}_{2}(\%)$ & $\mathrm{PEP} \mathrm{cmH}_{2} \mathrm{O}$ \\
\hline 30 & 5 \\
\hline 40 & 5 \\
\hline 40 & 8 \\
\hline 50 & 8 \\
\hline 60 & 10 \\
\hline 70 & 10 \\
\hline 70 & 10 \\
\hline 70 & 12 \\
\hline 80 & 14 \\
\hline 90 & 14 \\
\hline 90 & 16 \\
\hline 100 & 24 \\
\hline
\end{tabular}


Table 3: Biomarkers of interest

- Plasma soluble receptor for advanced glycation end-products (sRAGE, produced through the cleavage of full-length RAGE by proteinases, a marker of lung epithelial injury)

- Plasma angiopoietin-2 (a marker of lung endothelial injury)

- Plasma interleukin (IL)-8, bicarbonate, and tumour necrosis factor receptor (TNFr)-1 (markers previously used in a three-variable model that accurately distinguished a hyperinflammatory phenotype from a hypoinflammatory phenotype in patients with ARDS (Famous et al. Am J Respir crit Care Med 2016, DOI:10.1164/rccm.201603-06450C))

- Endogenous-secretory receptor for advanced glycation end-products (esRAGE, a RAGE isoform produced by alternative splicing)

- RAGE ligands: high mobility group box-1 protein (HMGB1), S100A12 and advanced glycation end-products (AGEs) 


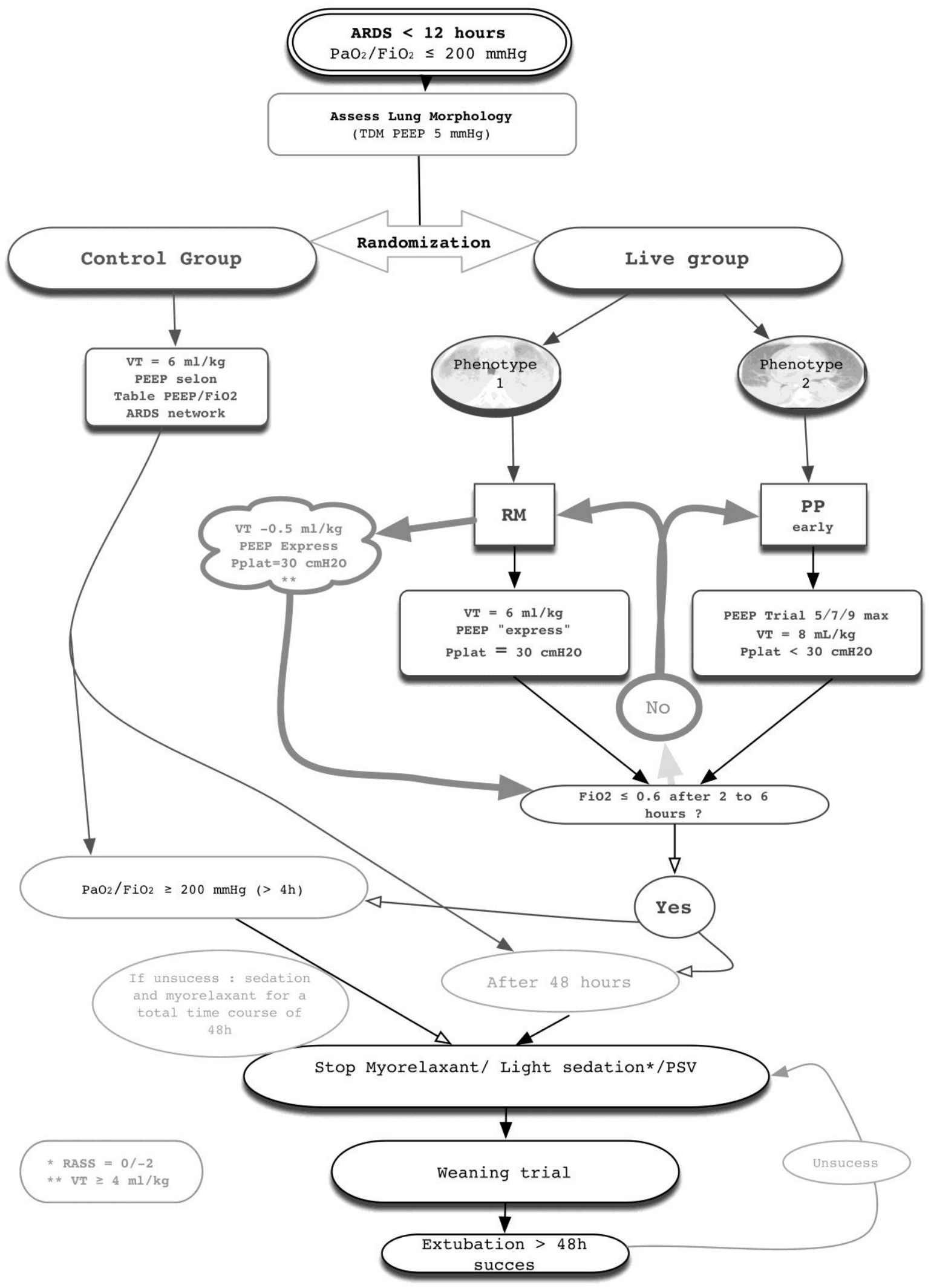


Page 20 of 20 